\title{
PENCEGAHAN INFEKSI PERINEUM DENGAN PERAWATAN LUKA PERINEUM PADA IBU HAMIL TRIMESTER III - NIFAS
}

\author{
Risa Pitriani' ${ }^{1)}$,Rita Afni' ${ }^{2}$ \\ ${ }^{1,2)}$ STIKes Hang Tuah Pekanbaru \\ Email: rita.afni@htp.ac.id
}

\begin{abstract}
ABSTRAK
Latar Belakang: Luka perineum adalah robekan yang terjadi di daerah perineum secara spontan atau sengaja digunting (episiotomi) untuk mempermudah kelahiran bayi. Robekan perineum terjadi pada hampir semua persalinan pertama dan tidak jarang juga pada persalinan berikutnya. Hampir $90 \%$ dari proses persalinan mengalami robekan perineum, baik dengan atau tanpa episiotomi.Tujuan:Diharapkan ibu hamil trimester III dan nifas ini nanti dapat mengetahui, melakukan, dan mensosialisasikan perawatan luka perineum pada masa nifas dengan tepat di wilayah kerja Puskesmas Rumbai Pesisir. Metode: Kegiatan yang dilakukan dengan cara memberikan pelatihan, penyuluhan, dan pemantauan evaluasi cara pewaratan luka perineum benar. Hasil: Pelaksanaan sudah terlihat bahwa tenaga kader cukup berperan dalam kegiatan ini yaitu terbukti pada saat pelaksanaan kegiatan tersebut ada 8 orang kader yang hadir dan membantu pelaksanaan kegiatan ini. Sedangkan penyuluhan bagi ibu hamil trimester III dan nifas memahami tentang pentingnya perawatan luka perineum pada masa nifas. Kesimpulan: Disarankan kepada pihak puskesmas agar melaksanakan kegiatan serupa di tempat yang berbeda serta mengadakan praktik cara perawatan luka perineum minimal 1 kali dalam setahun dan bagi kader yang telah mengikuti pelatihan agar dapat mensosialisasikan kepada ibu hamil pada saat kunjungan posyandu.
\end{abstract}

Kata kunci : perawatan perineum, ibu hamil trimester III dan nifas

\section{ABSTRACT}

Background: Perineal wounds are tears that occur in the perineal area spontaneously or deliberately cut (episiotomy) to facilitate the birth of a baby. Perineal tears occur in almost all first deliveries and not infrequently also in subsequent labor. Nearly $90 \%$ of childbirths experience perineal tears, either with or without episiotomy. Objective: It is expected that these third trimester and postpartum pregnant women will be able to know, do and socialize the care of perineal wounds during the puerperium in the working area of Rumbai Pesisir Health Center. Method: Activities carried out by providing training, counseling, and monitoring the evaluation of how to properly dye perineal wounds. Result: The implementation has shown that cadres play a significant role in this activity, which is evident that during the implementation of the activity there were 8 cadres present and assisting in the implementation of this activity. While counseling for third trimester pregnant women and childbirth understand about the importance of perineal wound care during the puerperium. Conclusion: It is recommended that the puskesmas conduct similar activities in different places and conduct practices on how to treat perineal wounds at least 1 time a year and for cadres who have attended training to be able to socialize to pregnant women during the posyandu visit.

Key words: perineal care, trimester III and postpartum pregnant women 


\section{PENDAHULUAN}

Pengetahuan ibu tentang perawatan pasca persalinan dan cara perawatan luka dapat menentukan lama penyembuhan luka perineum, ibu yang mengetahui cara untuk merawat luka perineum akan merawat lukanya dengan baik sehingga diharapkan bisa berpengaruh terhadap penyembuhan luka perineum. Perawatan luka bekas jahitan sangatlah penting karena luka bekas jahitan jalan lahir ini dapat menjadi pintu masuk kuman dan menimbulkan infeksi, ibu menjadi demam, luka basah dan jahitan terbuka, bahkan ada yang mengeluarkan bau busuk dari jalan lahir (vagina).

Berdasarkan data World Health Organization (WHO) pada tahun 2009 terjadi 2,7 juta kasus ruptur perineum pada ibu bersalin. Angka ini diperkirakan mencapai 6,3 juta pada tahun 2050, seiring dengan semakin tingginya bidan yang tidak mengetahui asuhan kebidanan dengan baik. Di Amerika, $40 \%$ dari 26 juta ibu bersalin mengalami ruptur perineum. Menurut penelitian di Australia, setiap tahun 20.000 ibu bersalin akan mengalami ruptur perineum. Di Asia ruptur perineum juga merupakan masalah yang cukup banyak dalam masyarakat, $50 \%$ dari kejadian ruptur perineum di dunia terjadi di Asia.

Prevalensi ibu bersalin yang mengalami ruptur perineum di Indonesia pada golongan umur 25-30 tahun yaitu $24 \%$ sedang pada ibu bersalin usia 31-39 tahun sebesar $62 \%$. Berdasarkan hasil penelitian yang dilakukan oleh Moloku (2013) ada hubungan antara pengetahuan tentang perawatan luka dengan penyembuhan luka episiotomi dan hasil penelitian Herawati (2010) ada hubungan antara perawatan perineum dengan kesembuhan luka perineum serta hasil penelitian Afni (2014) ada hubungan antara pengetahuan dan perawatan luka perineum dengan kesembuhan luka perineum.

Berdasarkan hasil survey yang dilakukan pada puskesams Rumbai pesisr didapatkan jumlah ibu persalinan sangat banyak terlihat dari data 2016 sekitar 360 jumlah kelahiran. Pada survey pendahuluan yang dilakukan pada BPM dince Safrina dari 10 ibu bersalin 6 orang mengatakan tidak mengetahui tentang cara perawatan luka perineum dan terdapat 2 orang yang mengalami infeksi pada luka perineum yang di sebabkan ketidak tahuan ibu tentang cara perawatannya.

\section{TINJAUAN PUSTAKA}

Luka perineum adalah robekan yang terjadi di daerah perineum secara spontan atau sengaja digunting (episiotomi) untuk mempermudah kelahiran bayi. Robekan perineum terjadi pada hampir semua persalinan pertama dan tidak jarang juga pada persalinan berikutnya. Hampir $90 \%$ dari proses persalinan mengalami robekan perineum, baik dengan atau tanpa episiotomi (Elva, 2012).

Penyembuhan luka perineum adalah mulai membaiknya luka perineum dengan terbentuknya jaringan baru yang menutupi luka perineum dalam jangka waktu 6-7 hari setelah persalinan (postpartum). Biasanya penyembuhan luka pada robekan perineum ini akan sembuh bervariasi, ada yang sembuh normal dan ada yang mengalami kelambatan dalam penyembuhannya, hal tersebut dapat dipengaruhi oleh beberapa hal diantaranya karakteristik ibu bersalin, status gizi, kondisi perlukaan dan perawatanya (Oxorn, 2003).

\section{METODE PELAKSANAAN}

Pengabdian ini dilaksanakan dalam bentuk penyuluhan dan pelatihan pada kader tentang cara perawatan luka perineum yang berada di wilayah kerja Puskesmas Rumbai Pesisir. Dalam kegiatan ini diawali dengan pelatihan, penyuluhan dan pembinaan pemantauan dan evaluasi. 


\section{HASIL DAN PEMBAHASAN}

Kegiatan pelatihan pada kader telah dilaksanakan pada hari Sabtu tanggal 30 Juli 2018 bertempatan di Posyandu Meranti Pandak Kecamatan Rumbai Pesisir dari kegiatan yang dilakukan di posyandu ada 8 kader yang mengikuti pelatihan perawatan luka perineum. Kegiatan pengabdian pada masyarakat ini memberikan hasil sebagai berikut:

- Pertemuan 1: Demonstrasi dan redemontrasi tentang perawatan luka perineum pada kader Dari demonstrasi yang dilakukan dari 8 kader 5 orang yang mengikuti pelatihan dengan baik.

- Pertemuan 2: Demonstrasi dan redemonstrasi tentang perawatan luka perineum pada ibu hamil trimester III dan ibu nifas

Dari demonstrasi yang dilakukan pada ibu hamil trimester III dan nifas terdapat $18 \mathrm{ibu}$ hamil dan nifas yang hadir pada pemateri yang dilakukan pada pertemuan diatas

- Pertemuan 3: Diskusi masalah perawatan luka perineum

Dari pemaparan yang telah di berikan terlihat kader dan ibu hamil trimester III dan nifas mampu menerima penjelasan dan mengaplikasikan pada saat ibu selesai bersalin.

Dari kegiatan yang sudah dilaksanakan pada pengabdian tersebut mendapatkan hasil sebagai berikut:

1. Meningkatkan pengetahuan kader tentang perawatan luka perineum

2. Kader dapat menjelaskan kepada ibu hamil tentang cara peawatan luka perineum

3. Kader dapat membimbing ibu hamil dalam pelaksanaannya

4. Kader mampu mengevaluasi hasil pelaksanaanya

a. Penyuluhan pada ibu hamil Trimester III dan ibu nifas

Kegiatan penyuluhan perawatan Luka Pada Perineumn di Desa Meranti Pandak Kecamatan Rumbai Pesisir.

Adapun karakteristik ibu yang mengikuti penyuluhan adalah sbb:

1. Ibu hamil Trimester III

2. Ibu hamil anak pertama

3. Ibu yang bersedia mengikuti penyuluhan dan bersedia melaksanakannya perawatan luka perineum dengan benar.

Dari hasil kegiatan yang telah dilakukan sudah terlihat bahwa ibu-ibu hamil cukup berperan dalam kegiatan ini yaitu terbukti pada saat pelaksanaan kegiatan tersebut ada 18 orang ibu-ibu hamil yang hadir dan membantu pelaksanaan kegiatan ini.

b. Pembinaan, pemantauan dan evaluasi

1. Pembinaan, dari kegiatan yang dilakukan oleh kader pada pengabdian masyarakat terhadap perawatan luka perineum. Kader yang berada pada posyandu melakukan kunjungan rumah pada ibu nifas sebanyak 2 kali dalam 1 minggu. Pembinaan yang dilakukan sesuai dengan tujuan pada pengabdian masyarakat yaitu ibu nifas harus mengetahui tentang cara perawatan luka perineum dan melakukan tentang cara perawatan luka perineum dengan tepat pada saat nifas.

2. Pemantauan, dilakukan oleh kader pada 12 ibu nifas selama 1 minggu dalam 2 kali kunjungan yang dilakukan menggunakan lembar observasi pemantauan luka perineum. Dari pemantau yang dilakukan awalnya $18 \mathrm{ibu}$ nifas yang mengikuti penyuluhan namun dilapangan hanya $12 \mathrm{ibu}$ nifas yang bersedia dilakukan observasi.

3. Evaluasi, dilakukan oleh kader terhadap ibu nifas sudah sesuai dengan tujuan, dari $12 \mathrm{ibu}$ nifas yang telah dilakukan observasi $10 \mathrm{ibu}$ nifas yang penyembuhan luka perineumnya memenuhi kriteria baik yaitu luka kering rata-rata 7 hari, perineum menutup dan tidak ada tanda infeksi (merah, bengkak, panas, nyeri, fungsioleosa). 
2 ibu nifas yang kategorinya sedangpenyembuhannya pada hari ke 11 dan hari ke 13 yaitu luka basah, perineum menutup, tidak ada tanda-tanda infeksi (merah, bengkak, panas,nyeri, fungsioleosa). Hal ini dikarenakan ibu tersebut masih enggan mengganti pakaian dalam dan pembalut pada saat selesai BAB dan BAK.

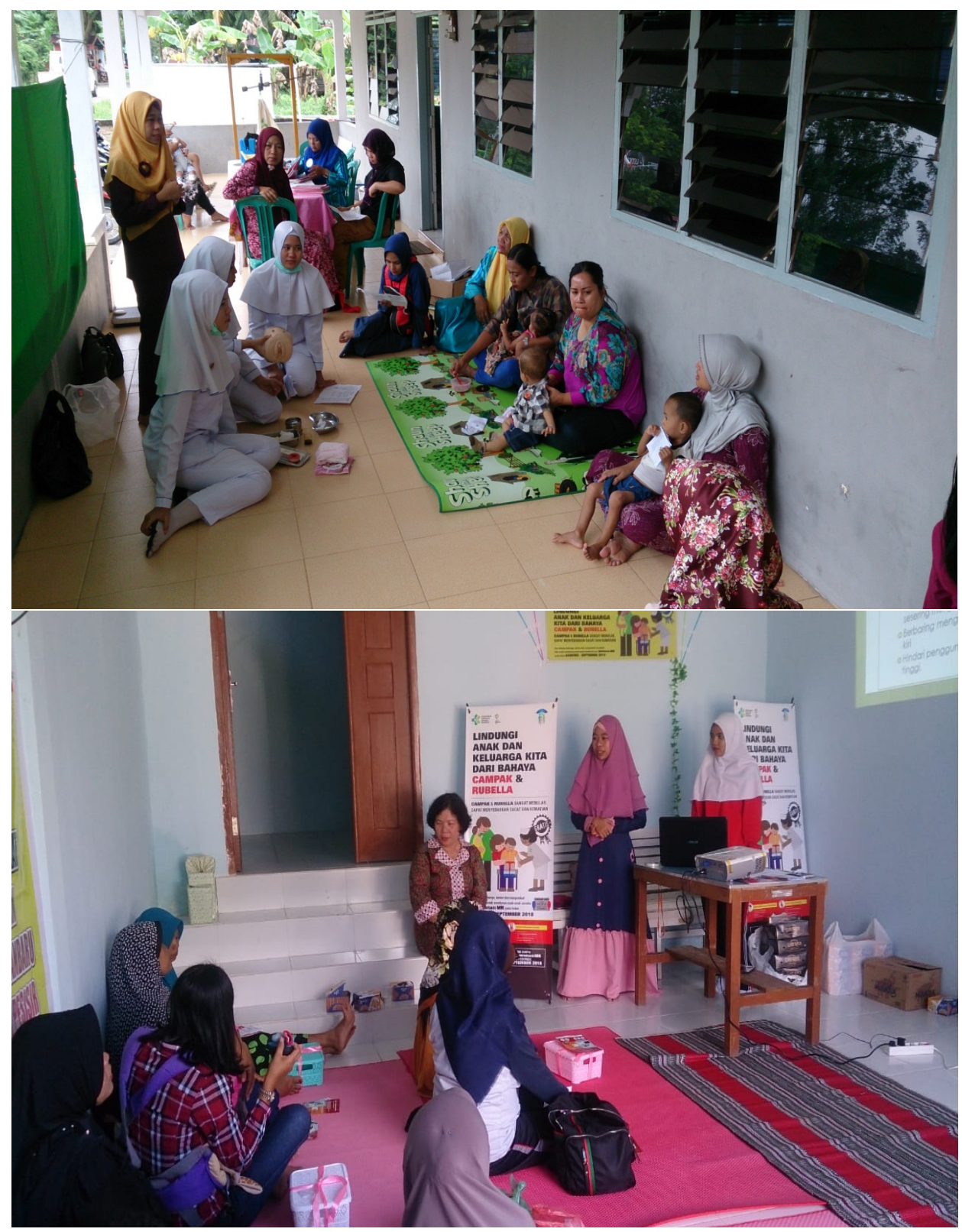

Gambar 1. Kegiatan Penyuluhan 


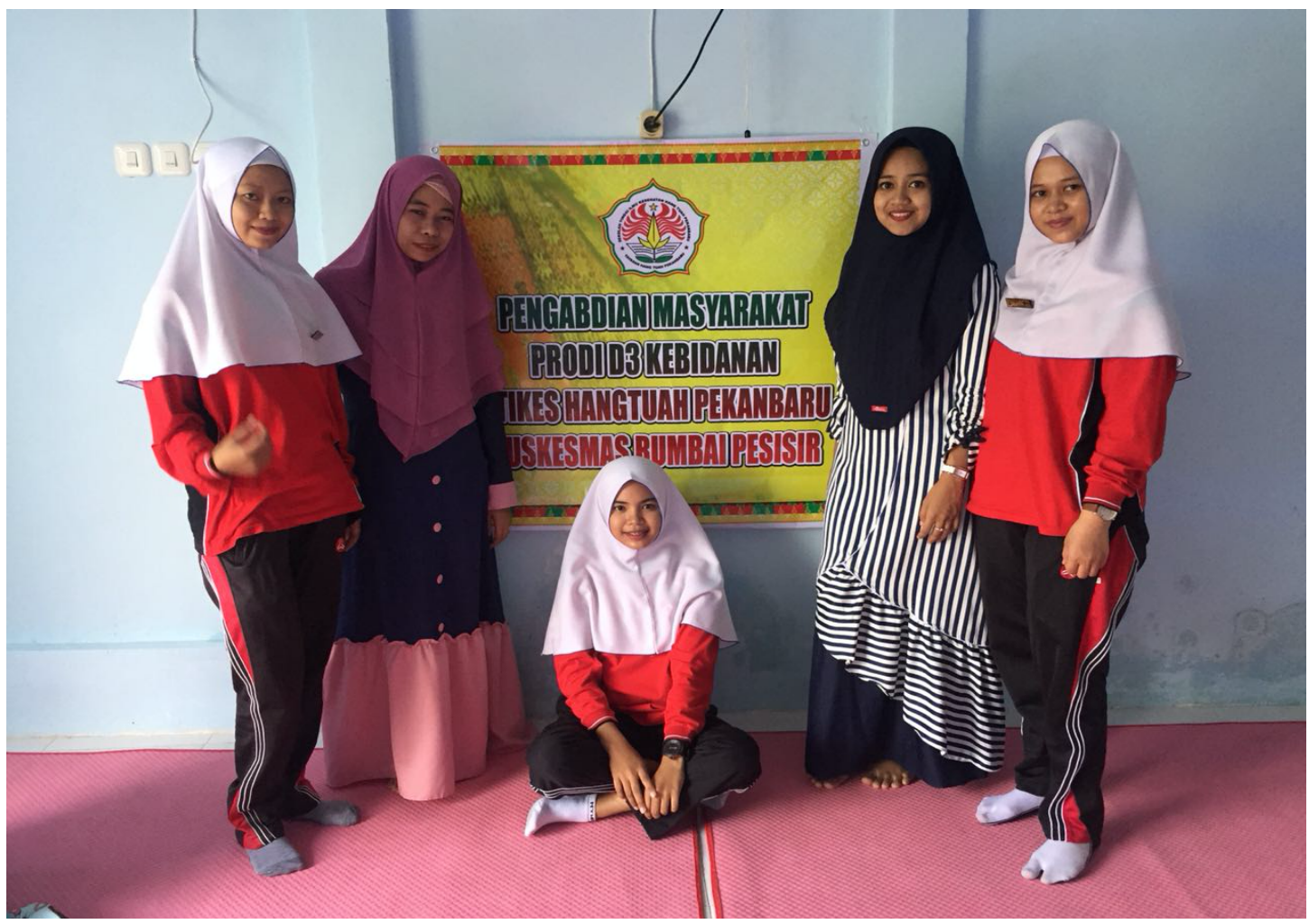

Gambar 2. Tim Pelaksana Kegiatan Pengabdian

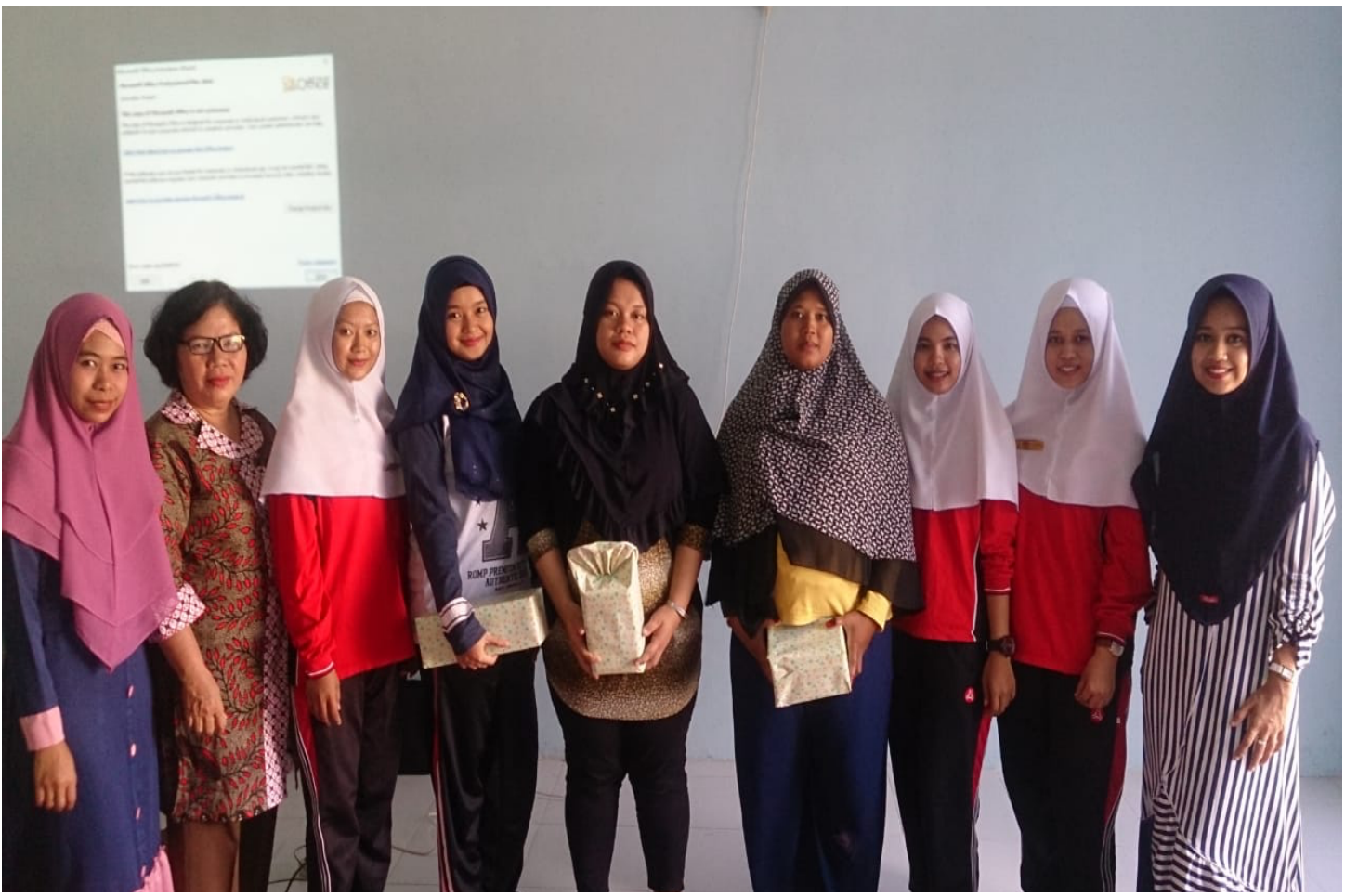

Gambar 3. Foto Bersama Peserta Kegiatan 


\section{KESIMPULAN}

Dari kegiatan pengabdian masyarakat ini dapat disimpulkan bahwa kader yang berada di wilayah kerja Puskesmas Rumbai Pesisir yang juga telah mendapatkan pelatihan tentang perawatan luka perineun dapat mendemonstrasikan tentang cara perawatan luka perineum kepada ibu hamil Trimester III dan nifas, selain itu juga dapat melakukan pembinaan melalui kunjungan rumah,melakukan pemantauan kepada ibu nifas melalui kunjungan rumah, serta mengevaluasi tentang hasil yang telah dicapai.

Pengetahuan ibu hamil trimester III dan nifas tentang pentingnya perawatan luka perineum terlihat meningkat, ibu nifas juga dapat melakukan perawatan luka perineum dengan sangat baik dan benar serta mengerti tentang cara perawatan luka perineum sehingga penyembuhannya lebih cepat.

\section{DAFTAR PUSTAKA}

[1]. Bahiyatul. 2009 . Buku Ajar Asuhan Kebidanan Normal. Jakarta : EGC

[2]. Depkes RI (2011) Asuhan Persalinan Normal. JHPIEGO. Jakarta

[3]. Elva (2012). Luka Perineum. http://elvantris.blogspot.com/2012/10/perineum. Diakses tanggal 3 Januari 2013

[4]. Indiarti, (2010). Persalinan dan Nifas. Jakarta : Indipress

[5]. JNPK.KR. 2008. APN, Jakarta: Yayasan Bina Pustaka Pramroharjo.

[6]. Manuaba. Endungan Et A1,2010. Ilmu kebidanan penyakit kanungan dan KB. Jakarta : EGC

[7]. Maritalia, Dewi (2012). Asuhan Kebidanan Nifas dan Menyusui. Yogyakarta. Pustaka Pelajar

[8]. Maryunani ,Anik.2009. Asuhan Pada Ibu Dalam Masa Nifas. Jakarta : Trans Info Media.

[9]. Oxorn, Harry (2003). Ilmu Kebidanan Patologi \& Fisiologi Persalinan. Human labor and birth. Yayasan Essentia Medica. Jakarta

[10]. Prawirohardjo, S (2006) Perawatan Maternal dan Neonatal. Jakarta. YBP-SP

[11]. Prawirohardjo, S (2007) Ilmu Kebidanan. Jakarta. YBP-SP

[12]. Prawiroharjo,sarwono .2009. Ilmu Kebidanan. Jakarta : PT.Bina pustaka.

[13]. Smeltzer S.C (2002). Buku Ajar Keperawatan Medikal Bedah. EGC. Jakarta

[14]. Suherni. (2009) Perawatan Masa Nifas. Fitramaya. Yogyakarta

[15]. Sulistyawati, dkk. (2010). Asuhan Kebidanan Pada Masa Nifas. Jakarta : Salemba Medika 